\title{
Evolutionary ecology of spoken language: co-evolutionary hypotheses are testable
}

\section{Carina Buckley and James Steele}

\begin{abstract}
Evolutionary ecological frameworks can give us new insights into the emergence of human adaptations such as language and cultural learning. There now exist several well-specified models of the social and ecological conditions in which the human capacity for language came under strong positive selection pressure. We critically review them, and ask how we can test them using archaeological evidence. We identify a series of critical archaeological and palaeontological parameters whose values we must know if we are to discriminate among competing hypotheses of the evolutionary ecology of language.
\end{abstract}

\section{Keywords}

Evolution of language; speech; vocal tract; group size; sexual selection; life history strategy; co-evolution.

\section{Introduction}

The questions of why and when language evolved in humans, and of why it did not in other branches of the primate order, have occupied researchers from a wide variety of disciplines, especially over the last few decades. Much work has been carried out on nonhuman primate vocal communication systems, on human brain evolution, on the evolutionary anatomy of human speech and, more recently, on possible selection pressures related to hominin social strategies (Knight et al. 2000).

Taken alone, no one of these approaches can hope to supply the answers sought. The evolution of language could not have occurred without the co-option of highly complex anatomical and neurological systems to a degree not seen elsewhere in the animal kingdom. But language, more than that, is also a social tool, and this context must be considered to be at least as important when determining the selection pressures for its emergence. This context can be studied using the methods of evolutionary ecology, which 
may be described as 'the application of natural selection theory to the study of adaptation and biological design in an ecological setting' (Smith and Winterhalder 1992: 5). This paper will address these issues in an attempt to create a more coherent synthesis of current research into this problem, and to identify the crucial parameters from each area of study that must be defined in order to understand the social context of language evolution.

The first task is to address the emergence of language as a product of natural selection and therefore under the influence of a variety of environmental pressures over the course of evolutionary time. This idea has not been without its controversy, most notably tackled by Pinker and Bloom in an insightful 1990 paper. To many researchers, language has not appeared to show any genetic variation, to exist in any intermediate forms or to confer an obvious selective advantage; and it seems to require more evolutionary time and genomic space than is available (Pinker and Bloom 1990: 707). Prominent opponents of the natural selection impetus behind language are Noam Chomsky and Steven Jay Gould, who both argue that language may be simply a 'side effect' of other evolutionary forces such as an overall increase in brain size (Pinker and Bloom 1990: 708). Gould specifically suggests the term 'exaptation' (Gould and Vrba 1982) to describe the process whereby new uses are made of parts that were originally adapted to some other function (Pinker and Bloom 1990: 709). However, structures produced entirely by non-adaptive mechanisms are generally one-part or repetitive shapes or processes that correspond to simple physical or geometric laws. Spandrels, exaptation and other explanations are the bases of what natural selection has to work with (Pinker and Bloom 1990: 710).

Language has specific features that appear to be highly adaptive. For all the things that a speaker may wish to do with language, such as talk about events and states, distinguish the participants in the event or state according to role, or comment on the time and duration of an event or state, grammar is able to provide that ability. It can map propositional structures onto a serial channel, minimizing ambiguity in context while constrained by the need for high-speed encoding and decoding, according to a code shared by an entire community of potential communicators (Pinker and Bloom 1990: 713). In order for this to have resulted from natural selection, there must have been variability among individuals in terms of their grammatical competence, and the process from no language to language as we speak today must have been gradual, with each step being small enough to have stemmed from a random mutation which conferred enough advantage to have been fixed into the population. Pinker and Bloom argue that our current knowledge of language and of evolution make each of the above postulates plausible (1990: 721).

Moreover, language has costs. Physically, it has been suggested that the distinctive human trait of a lowered larynx in the throat has incurred a higher risk of death from choking, as the downward movement has caused us to lose the ability to swallow and breathe at the same time (in human babies and chimpanzees, the larynx is high enough for the soft palate and epiglottis to meet and close off the trachea while liquid flows harmlessly down the oesophagus (Laitman et al. 1978: 467-8)), as the pharynx is a common pathway for food, liquid and air in human adults (Lieberman et al. 1972: 291). However, it has been suggested recently (Clegg and Aiello 2000: 126) that this increased risk of choking may have been exaggerated somewhat, as it was found that overall mortality from choking on food over the last 100 years averaged 0.6 per 100,000 head of the population.

There are social costs too, perhaps of a more significant nature than the one suggested 
above. Language may allow an individual to become part of a social group, through the exchange of information and common symbolic understanding, but this comes at the often-overlooked consequence of being 'locked' into a speech community. When individuals learn a language, they 'construct their system of verbal behaviour to resemble that common to the group or groups with which [they] wish from time to time to be identified' (LePage 1968: 192). The development of dialect and linguistic diversity may function to constrain human mobility. The 'free rider', who moves ruthlessly and exploitatively from group to group, 'could not possibly survive in populations where each local group had its own language or dialect. Each group would be able to tell by his speech that he was an outsider and where he came from' (Nettle and Dunbar 1997: 98).

For language to have developed in the way it did, there must therefore have been social preconditions, as well as the necessary physical modifications. As a social adaptation, language equips individuals with the ability to transfer and receive information, including about people, objects and places not present, and to manage relationships with other individuals. It is likely that anatomical specialization for language evolved in tandem with the social context of language use, as part of a gene-culture co-evolutionary process.

Both sides of the foregoing debate (Pinker and Bloom versus Chomsky and Gould) take it as axiomatic that natural language structure has a genetic basis. An important alternative perspective is the self-organizing systems approach, which argues that a language community is a complex adaptive system in which 'language behaviour becomes canalized because the more members of a community adopt the same convention, the stronger the convention will become' (Steels 1997; see also Kirby (2001) for a recent 'selforganizing' perspective). In this approach, there is no genetically-encoded 'language organ' (whether or not the subject of natural selection); rather, natural language features become fixed by conventionalization, and the evolution of language is in this sense a side effect of cultural transmission and adaptation underwritten by an innate general substrate of cognitive, perceptual and motor abilities. A synthesis of the genetic and the selforganizing perspectives is, however, provided by the hypothesis of a 'Baldwin effect', in which - as language emerges through self-organization and becomes perpetuated by cultural transmission - individual variability in features advantageous to language production and comprehension becomes subject to natural selection, leading to 'genetic assimilation' of linguistic structures.

For our purposes here, the difference of perspective between those favouring a 'language organ' and those favouring genetic assimilation is secondary. In each case, some model of hominin social dynamics is a prerequisite for the emergence of linguistic structure and its anatomical underpinnings. The pure self-organizing perspective (without genetic assimilation) we take to be refuted by numerous independent lines of evidence for adaptation in the vocal production system, reviewed below. The aim of this paper is to determine these social preconditions and how they must have interacted with the evolution of human anatomy in order to make the emergence of language possible, if not inevitable. This will be achieved through the study of independent markers in the fossil and archaeological records of social system evolution and of language/speech evolution (noting that 'language' refers to the cognitive capacity while 'speech' implies the physical ability). By determining the visibility of relevant parameters for language-social system 
co-evolution, we hope to highlight areas that need to be further investigated through archaeological research.

\section{Social models of language evolution}

Numerous recent studies have proposed social preconditions for the evolution of language (summarized in Table 1). We have organized them along three major dimensions of social variability; they are parenting strategy, status and rank, and co-operation. It seems to us that models can be differentiated according to the emphasis they give to, respectively, the evolution of extended provisioning networks and the costs of rearing large-brained offspring; the sexual selection of high linguistic competence in preferred mates; and the co-evolution of language and social co-operation in stable social groups. In order to simplify our analysis, we shall caricature the options in terms of three extreme models.

The first set of models emphasizes the stabilization of kinship networks and the extension of provisioning effort for the rearing of offspring to include both males and female kin (e.g. 'grandmothers'). In this model, the effectiveness of alliance networks enables a mother to rely on other individuals, envisaged as close kin relations, to assist in the provisioning and nurturing of the female's offspring. The supposed benefit of such a situation is to ensure gene survival over multiple generations. Language serves both to optimize the task of co-operative food search and to enforce social contracts linking provisioning effort to reproductive success.

In the second set of models, the emphasis is on sexual selection of mates who are either verbally adept or who are able to communicate information that is useful to other members of the group. In its extreme form, such a model would see linguistic interaction as a competition for social dominance and for consequent preferential access to fertile mates.

In the third set of models, language is seen as dependent on the co-operative interactions of members of the proto-linguistic community. In one extreme form, it has been suggested that language evolved as a time-efficient means of servicing affiliative relationships in groups whose size had become too large for social grooming to have remained an effective strategy for social cohesion.

We may note at once some significant contrasts in the predictions derived from each such group of models. In the kinship-oriented models, there is no supposition of unusually large group sizes, while the emphasis on parenting effort precludes any emphasis on intense male-male competition for mating opportunities (which would tend rather to favour adaptations to mating effort). In the competition models, the emphasis is on verbal displays of reproductive fitness, and the expected correlate would be intensified agonistic interactions among members of the same sex and an emphasis on mating rather than parenting effort. In the group size models, the emphasis is on social manipulation in increasingly complex social groups under time constraints, and there is no assumption of any linkage either to more intense parenting effort and co-operative provisioning or to more intense mate competition. 


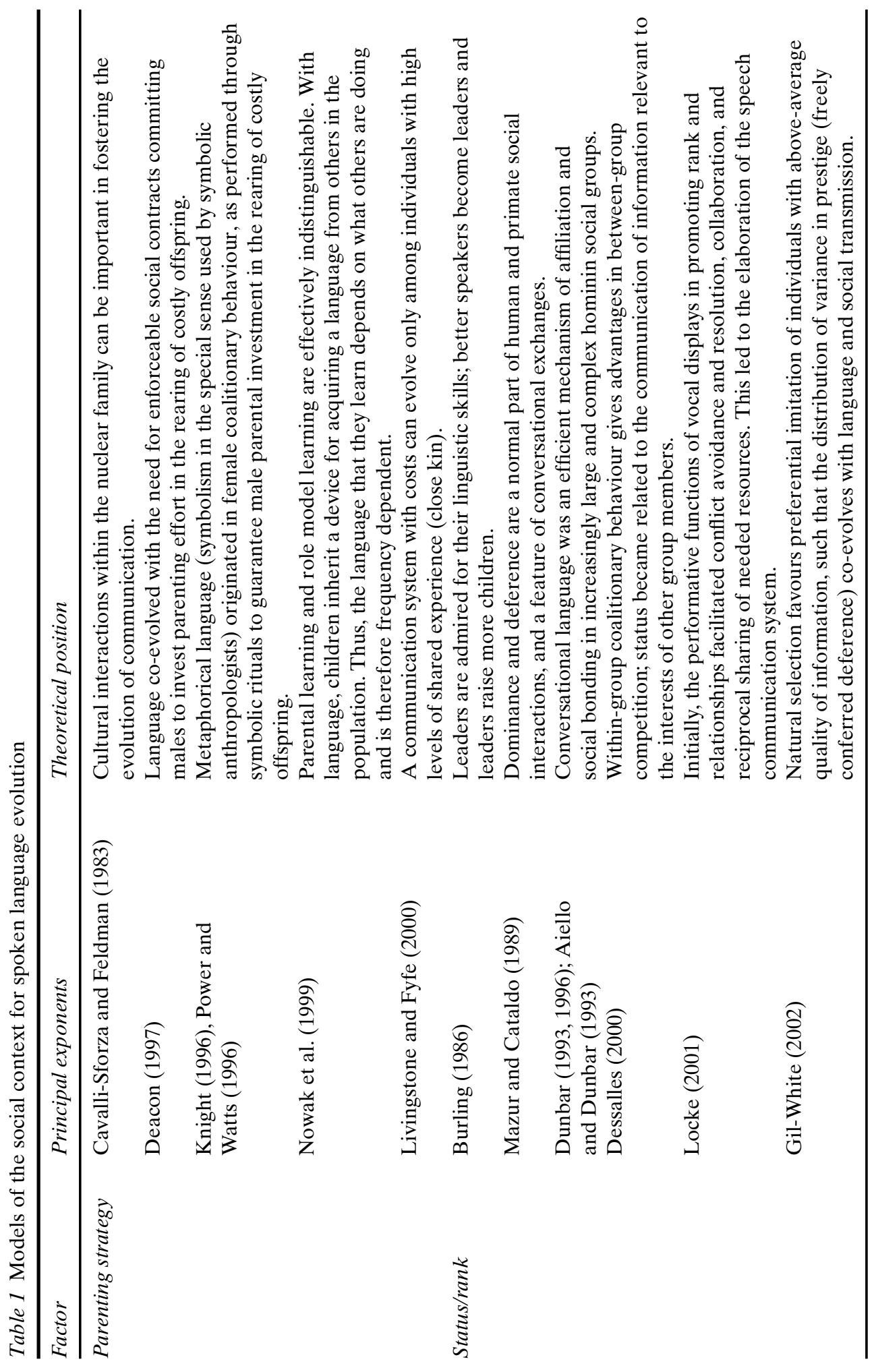




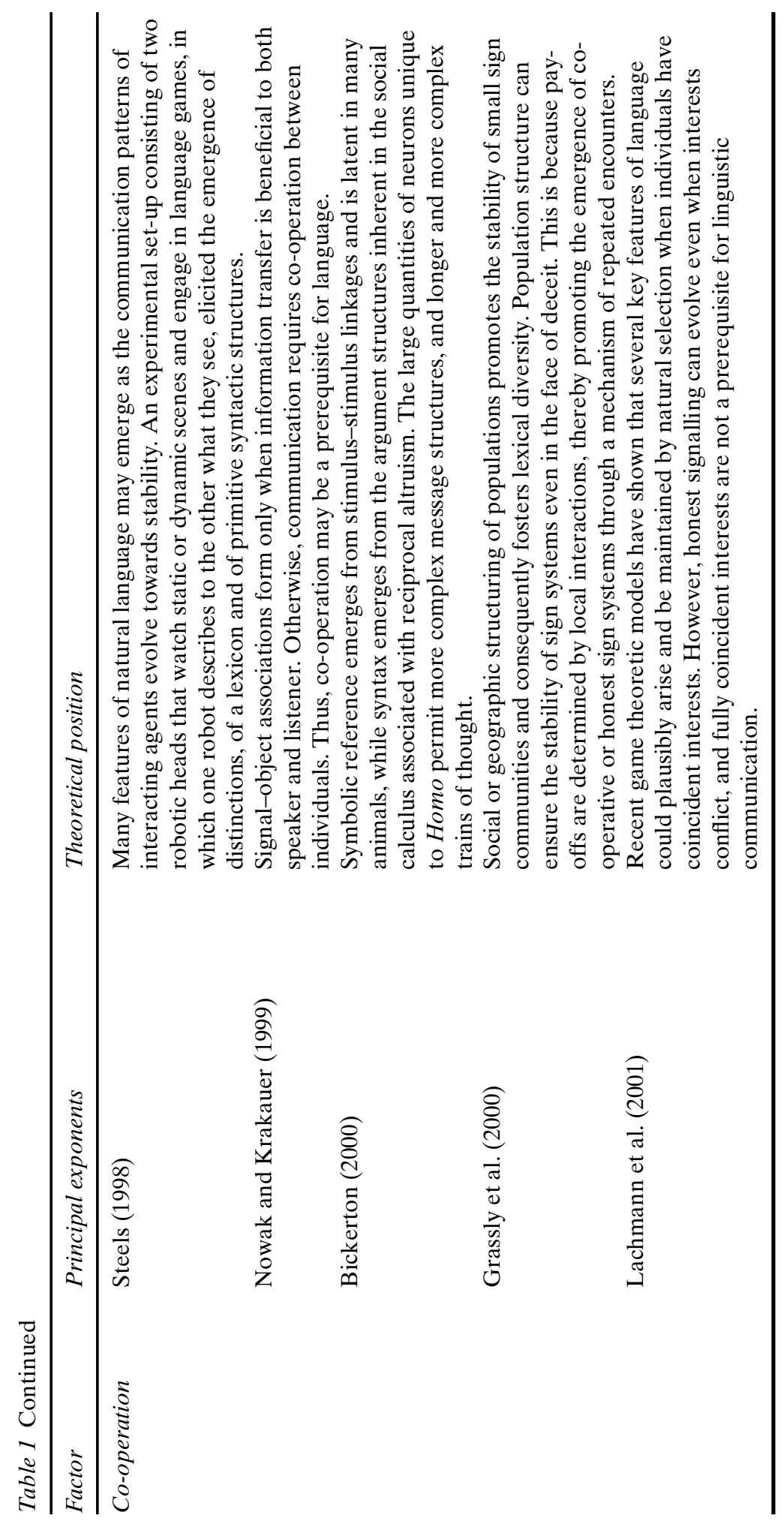




\section{The evolution of hominin social systems}

We now turn to a consideration of the anatomical and archaeological evidence for the evolution of hominin social systems. Again, these diagnostic markers may be clearly separated into three distinct emphases: parenting strategy; competition level; and group size (see Tables 2 and 3). The division into anatomical and archaeological evidence allows us to assess the different pressures focused on in a range of models.

Classically, palaeoanthropologists emphasize the evolution of life history in the hominins, with an emphasis on the implications of encephalization for maternal energetic costs in child rearing, and thus for parenting strategy. Large brains imply extended periods of immaturity (secondary altriciality), while the prolongation of foetal brain growth rates into the first year of postnatal life imposes a substantial energetic burden on lactating mothers. One of the major questions in hominin evolution relates to the timing of the evolution of cultural strategies for extension of provisioning effort to others than the biological mother. Similarly, much archaeological work has focused on the question of whether or not early African Palaeolithic sites represent home bases or central places to which foragers brought food resources (notably, animal carcass elements) for sharing, as a proto-human strategy (in Isaac's (1989) sense) of group provisioning.

With respect to intensification of mate competition, hominin fossil anatomy points to a reduction in adult sexual dimorphism of body mass and canine size (and hence of malemale competition), which does not suggest that male-male competition for mates was a driver for the evolution of social communication strategies. In the archaeological record, Kohn and Mithen (1999) have argued that Lower Palaeolithic handaxes - the first clearly elaborated and standardized stone artefact tradition - served to advertise the fitness of their makers in a context of intense male-male competition. However, Steele (1994) has suggested, on the basis of simulations of cultural diffusion, that stability of artefact form in space and time of the order seen in the Acheulean handaxe tradition implies functional adaptiveness in their design. Shennan and Steele (1999) have proposed that the cultural transmission of complex craft skills is a form of parental investment in the extractive foraging capability of offspring, such that the handaxe tradition - if it gives functional advantages to its practitioners in food processing - should be seen not as a sign of runaway sexual selection of a non-adaptive cultural display, but as a sign of increased parenting effort. Thus, the archaeological evidence for intensification of mate competition hinges on the interpretation of this artefact tradition as involving non-adaptive investment in standardization, elaboration and symmetry of form. If such traits give a functional advantage in extractive foraging tasks (notably, animal carcass resource processing), then Kohn and Mithen (1999) are refuted.

With respect to group size and the 'vocal grooming' argument, testing the hypothesis relies upon the single anatomical marker of relative neocortex size, as predicted from endocranial volume, which is intended to stand as a proxy for average group size and social complexity, and hence as a marker for the number of social relationships that an individual can keep track of. However, it has been shown (Steele 1996) that the correlation between endocranial volume and social group size in primates is fairly weak, to the extent that hominin group sizes cannot reliably be predicted from brain capacity measures. 


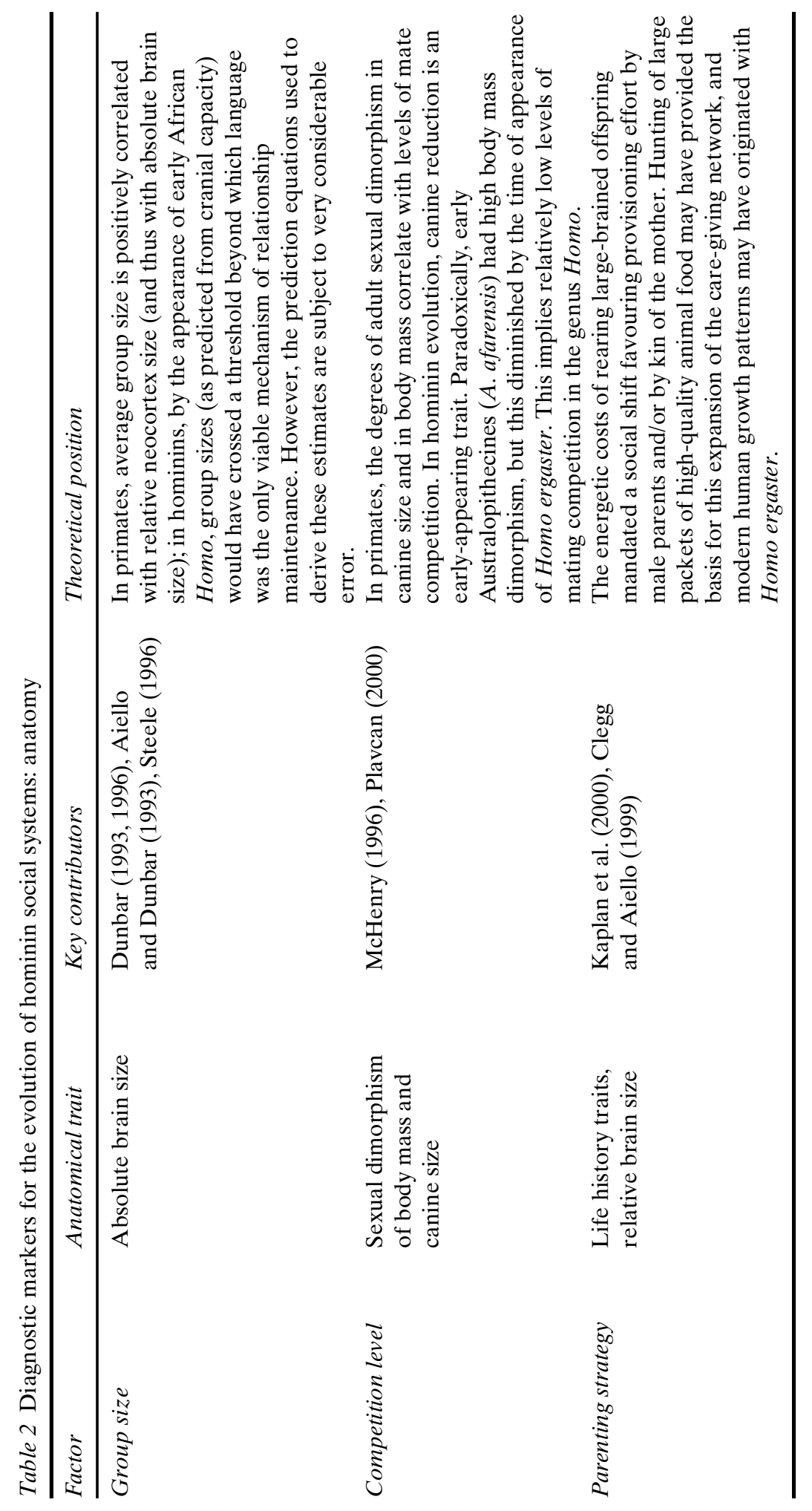




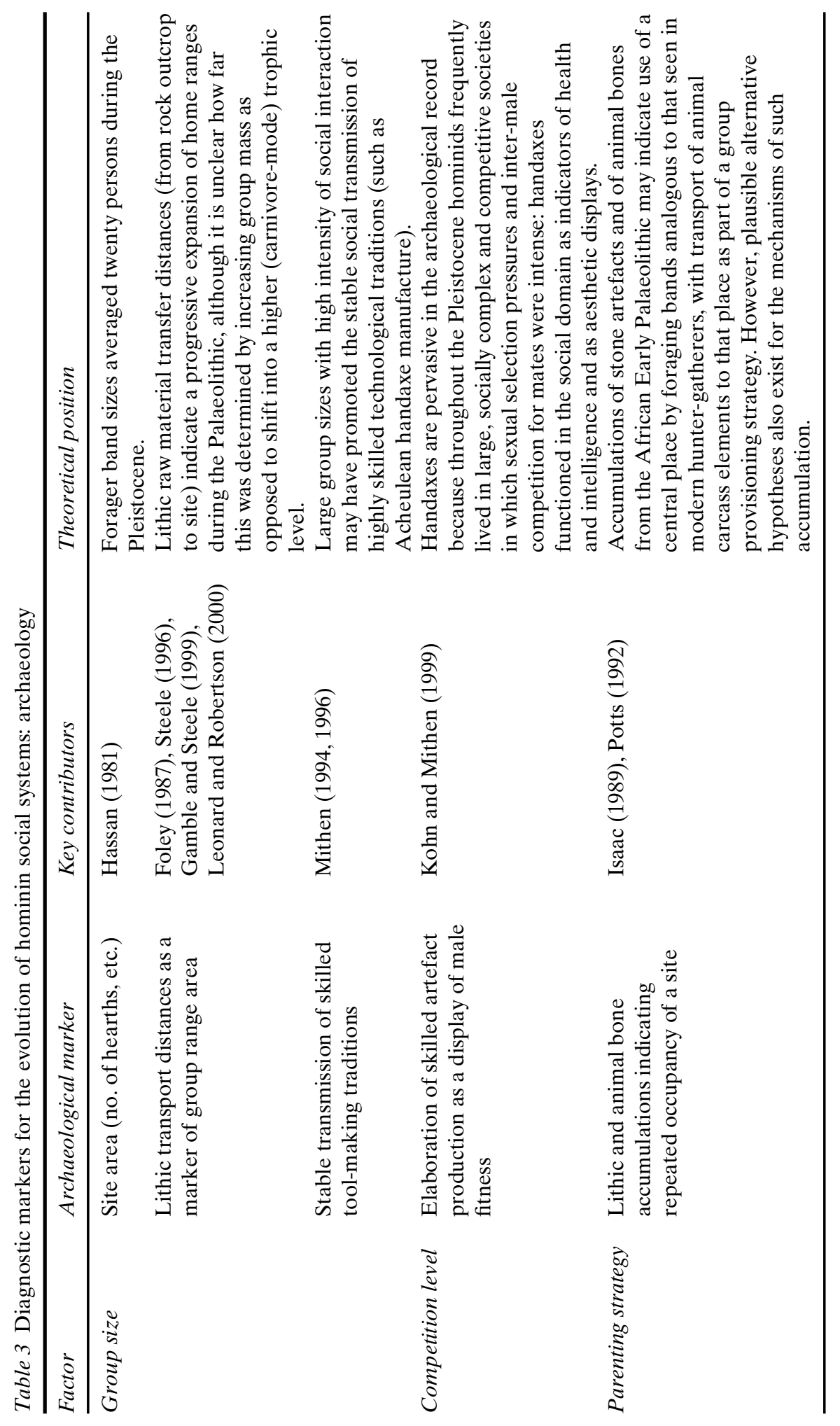




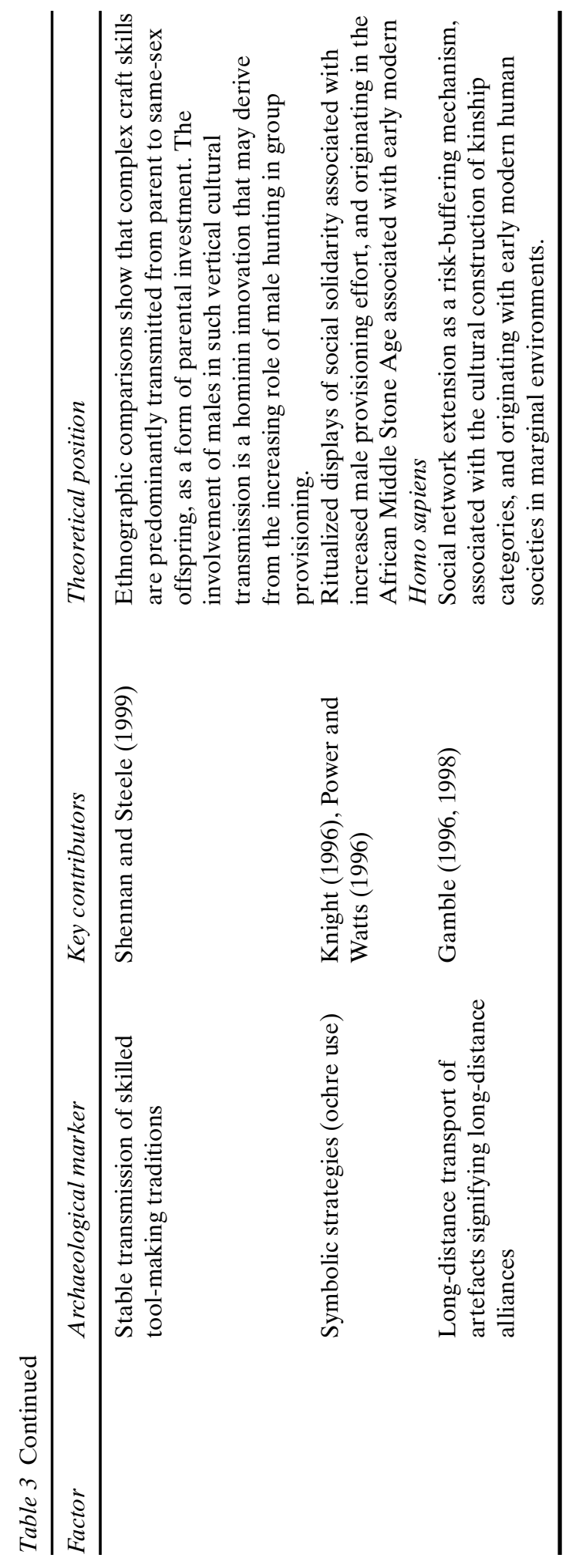


The archaeological evidence for hominin social group sizes includes site area and the number of hearths, and home range area (as a function of group biomass). The first of these sources relies on the supposition that a greater number of hearth sizes indicates a larger social grouping and therefore an opportunity for language evolution, if the "vocal grooming' hypothesis is followed. This may not be a wholly reliable estimator of the level of activity on a site, as the habitual use of a site by a particular group over time will ultimately expand the size of the area because of overlap caused by a lack of precision in the location of recurrent activities. However, what evidence we do have suggests that coresidential social groups were relatively small throughout the Pleistocene. Group home ranges, as indicated by lithic transport distances, certainly far exceed those seen in contemporary non-human primates and become progressively greater through the Palaeolithic; however, the possible association with enlarged social groups is confounded by the shift in this period to greater dietary dependence on animals (Gamble and Steele 1999). Carnivores tend to have home ranges an order of magnitude greater than those of primates, while carnivores in high latitudes range yet more widely - due to the sparser concentration of feeding resources respectively at the higher trophic level and in the less productive and more seasonal environments. The reliance on animal-based protein and hunting would have selected for smaller, more mobile groups, overall reducing the plausibility of the evolutionary existence of large co-residential social groups, which are therefore an unlikely driver for the evolution of language. Mithen $(1994,1996)$ has proposed a third source of indirect evidence for large social groups, namely the social transmission of skilled, complex technological traditions. However, the validity of this proposal rests on the correlation between such Lower Palaeolithic artefact traditions and habitat characteristics favouring large social aggregations, and this has been undermined by demonstrations of the occurrence of the artefact traditions in environments antithetical to those which Mithen suggests would have selected for intense sociality (McNabb and Ashton 1995; McNabb 1996).

Thus, it remains to conclude that the most plausible social explanation for the evolution of language is intensely negotiated co-operation within small stable groups, based on family or kinship ties. Language enhances efficiency in co-operative foraging tasks, particularly where this involves monitoring resource condition across dispersed patches at large space scales ('topographic gossip', Widlok 1997), or where this involves the social transmission of categorical distinctions that enable discrimination of food items by their nutritional value (Cangelosi et al. 2000). Language also enables the negotiation of food sharing - according to Eibl-Eibesfeldt (1989: 525-6), the majority of all !Kung conversations centre on food, and many ethnographically documented food conversations are concerned with social aspects - 'who gives what to whom, and criticisms of those who do not share their food'. Social stability is reinforced by the symbolic development of classificatory kinship terms that discriminate between degrees of relatedness and therefore degree of co-operation. Language is consequently vital to distinguish between members of the kinship group and the importance of their relatedness to an individual - and the social contracts that are entailed in relations between individuals of defined kinship categories. 


\section{Evidence for the capacity for language}

Finally we come to a review of the anatomical and archaeological markers for the evolution of language (see Tables 4 and 5). The existing literature remains unclear over the nature of the adaptations that took place in hominin evolution. There is no consensus over whether the brain underwent remodelling in favour of selection for language or whether existing elements were co-opted or modified from existing functions. This pits the idea of a novel 'language organ' against the observed conservatism of the mammalian brain, and anatomical studies so far have not identified a unique language-related structure within the human brain that would be preserved in fossil hominids, so the argument must continue for the time being. Perhaps the clearest indicator available that there has been some kind of significant reorganization (whether quantitative or qualitative) of the human brain is lateralization of function, seen in human population-level right-handedness (McGrew and Marchant 1997). No other primate demonstrates the human condition to anywhere near the same degree, and it is sometimes argued that this is an artefact of selection for a specialized speech area in the left hemisphere. Predominant right-handedness is evident as far back as Homo ergaster, and certainly by the time of the Neanderthals. However, and perhaps paradoxically, the brain morphological asymmetries that have been associated with this functional trait do not appear to be evolutionarily novel in the hominin line (Steele 2000, in press).

While evidence for language selection within the brain is not easy to interpret, it is more clearly seen that other features of the anatomy necessary for speech in its modern form were under natural selection. Traits of the human vocal articulatory system that have been interpreted as the focus of past selection pressures include vocal tract morphology (the descended larynx), speech-related musculature (the presence of slow tonic muscle fibres in the larynx, pharynx and tongue) and motor innervation of speech-related structures including the thoracic wall, tongue and jaw. These traits are interrelated: for instance, the denser motor innervation of the tongue is matched by the variance between humans and chimpanzees in the angles of inclination of the tongue and larynx muscles, which limit the number and quality of articulatory target areas that the chimpanzee tongue can reach, when compared to humans (Duchin 1990). Studies of fossil hominin anatomy indicate the emergence of these adaptations within the genus Homo, although debate continues regarding individual traits' presence or absence in Homo ergaster, Homo erectus and Neanderthals.

The descent of the human larynx is considered crucial to the investigation of language evolution because it creates a pharyngeal cavity separate from the buccal cavity, with the result that a greater range of vowel sounds can be produced. The position of the hyoid bone is a marker of laryngeal position and thus of vocal tract morphology. However, there have been difficulties in reconstructing the condition in past hominins. The supralaryngeal vocal tract does not fossilize, but it is thought to be affected by the degree of flexion of the basicranium. It appears likely that the basicranium was not flexed to a sufficient degree until the emergence of Homo sapiens, but it should not be assumed that this automatically means that Neanderthals were incapable of speech: evidence suggests that cranial base flexion is not a reliable predictor of hyoid position in humans or other primates, and so cannot be extrapolated back into the past. 


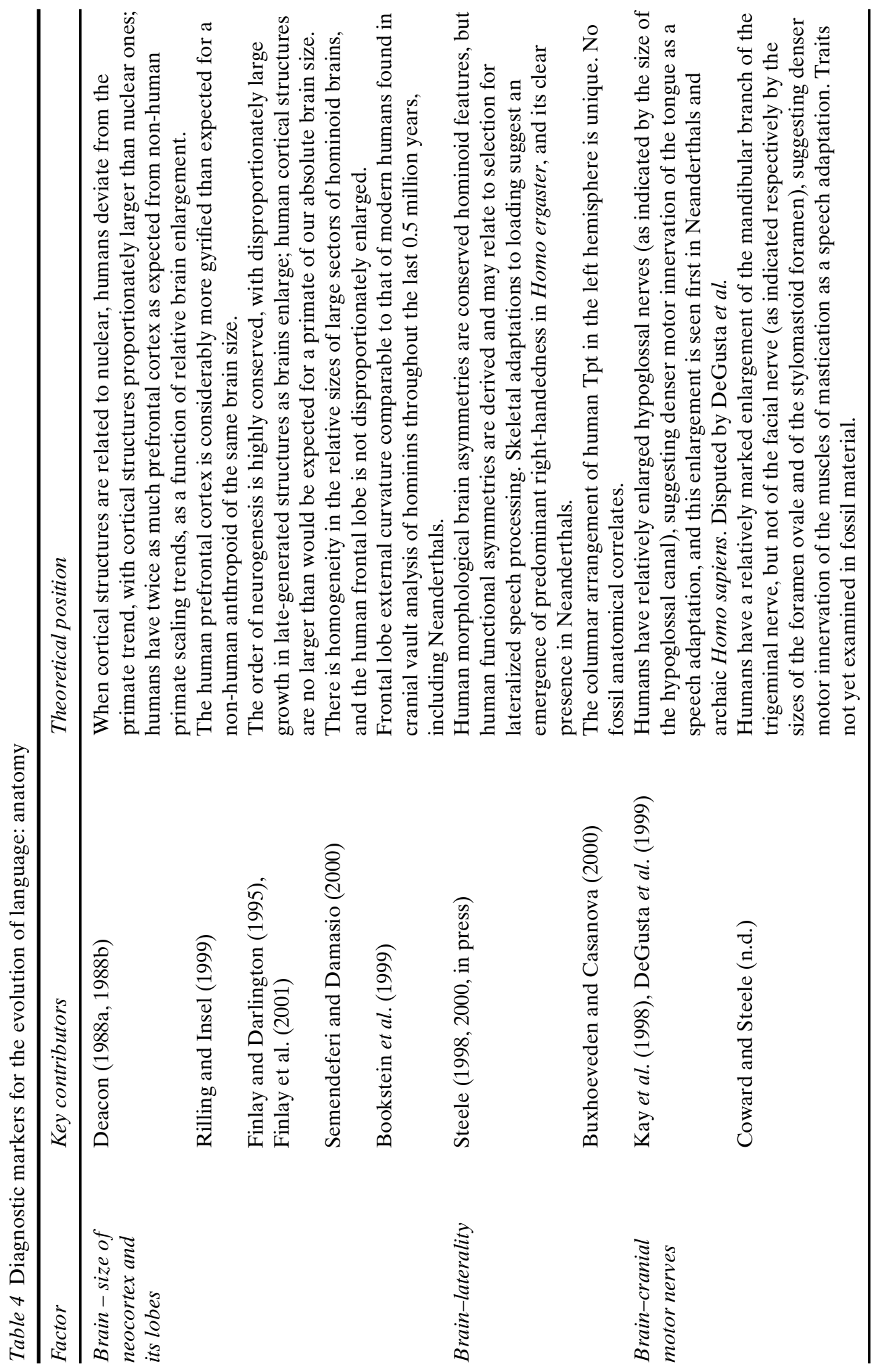




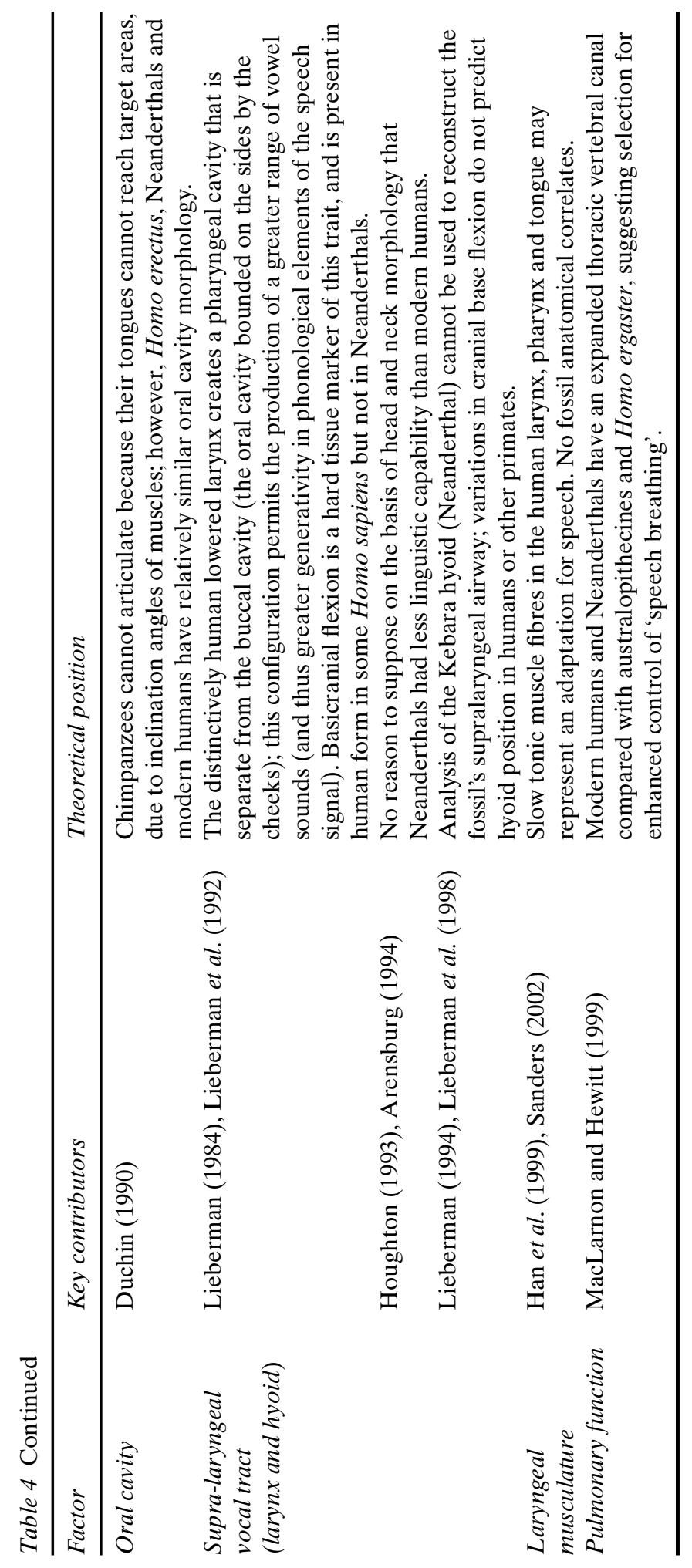




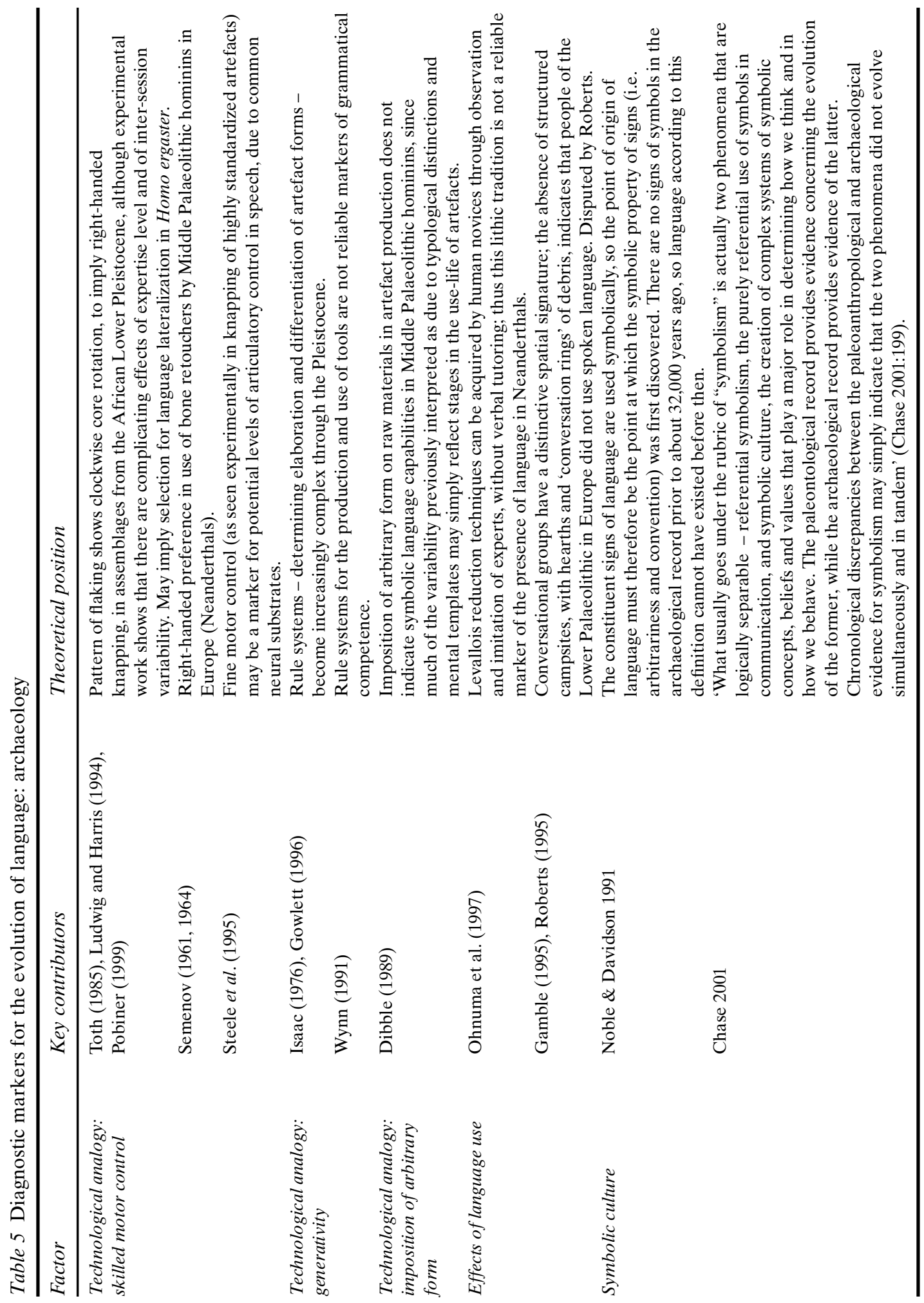


Unfortunately, the archaeological record does little to confirm or deny the presence of language. Technological analogies such as manipulative skill, right-hand preference, symmetry or standardization of form are not direct markers of the emergence or presence of language. While it is possible or probable that there are homologies of skilled movement and of the organization of production in the technological and in the linguistic domains, the evolution of features in the former can tell us only about the potential for elaboration of homologous features in the latter. Directly, they function only to indicate the development of skills, or lateralization, or different methods of tool production. These can tell us only about the priorities of the toolmaker, or selection pressures acting upon the mode of production. As such, they cannot be interpreted as indicators for the presence or otherwise of language.

We are still a long way from reliable recognition of more direct indications of everyday language use in pre-sapiens hominin societies, such as evidence for verbal transmission of craft skills or for spatial structuring of campsite activities indicative of conversational spacing. Thus it is the anatomical record of the evolution of articulatory ability, and not the archaeological record of technological traditions, that is most likely to give us reliable controls on the chronology of language evolution.

\section{Discussion}

Our review of social models of language evolution has suggested that three extreme variants can be proposed, which focus (respectively) on the social correlates of hominin life history strategy, of intensified mate competition and of increased group sizes. Our review of the anatomical and archaeological markers of social evolution suggests that neither intense mate competition nor the management of affiliative ties in very large coresidential social groups were the drivers of language evolution. We are left with the hypothesis of life history strategy as the prime mover, and co-operative foraging and provisioning as the selective context for spoken language abilities. Our archaeological focus must therefore be on the co-evolution of the human life history strategy and of speech adaptations in the genus Homo.

Department of Archaeology

University of Southampton

\section{References}

Aiello, L. C. and Dunbar, R. I. M. 1993. Neocortex size, group size, and the evolution of language. Current Anthropology, 34: 184-93.

Arensburg, B. 1994. Middle Palaeolithic speech capabilities: a response to Dr Lieberman. American Journal of Physical Anthropology, 94: 279-80.

Bickerton, D. 2000. Resolving discontinuity: a minimalist distinction between human and nonhuman minds. American Zoologist, 40: 862-73.

Bookstein, F., Schafer, K, Prossinger, H. et al. 1999. Comparing frontal cranial profiles in archaic and modern Homo by morphometric analysis. Anatomical Record, 257: 217-24. 
Burling, R. 1986. The selective advantage of complex language. Ethology and Sociobiology, 7: 1-16. Buxhoeveden, D. and Casanova, M. 2000. Comparative lateralisation patterns in the language area of normal human, chimpanzee and rhesus monkey brains. Laterality, 5: 315-30.

Cangelosi, A., Greco, A. and Harnad, S. 2000. From robotic toil to symbolic theft: grounding transfer from entry-level to higher-level categories. Connection Science, 12: 143-62.

Cavalli-Sforza, L. L. and Feldman, M. W. 1983. Paradox of the evolution of communication and of social interactivity. Proceedings of the National Academy of Sciences of the USA, 80: 2017-21.

Chase, P. G. 2001. Symbolism is two different phenomena: implications for archaeology and paleontology. In Humanity from African Naissance to Coming Millennia (eds P. V. Tobias, M. A. Rath, J. Moggi-Cecchi and G. A. Doyle). Florence: Firenze University Press, pp. 199-212.

Clegg, M. and Aiello, L. C. 1999. A comparison of the Nariokotome Homo erectus with juveniles from a modern human population. American Journal of Physical Anthropology, 110: 81-93.

Clegg, M. and Aiello, L. C. 2000. Paying the price of speech? An analysis of mortality statistics for choking on food. American Journal of Physical Anthropology, Suppl. 30: 126.

Coward, F. and Steele, J. in prep. Innervation of the muscles of the face and jaw: its role in the evolution of modern human speech. Manuscript.

Deacon, T. W. 1988a. Human brain evolution: I - Evolution of language circuits. In Intelligence and Evolutionary Biology (eds H. Jerison and I. Jerison). Berlin: Springer-Verlag, pp. 363-81.

Deacon, T. W. 1988b. Human brain evolution: II - Embryology and brain allometry. In Intelligence and Evolutionary Biology (eds H. Jerison and I. Jerison). Berlin: Springer-Verlag, pp. 383-416.

Deacon, T. W. 1997. The Symbolic Species: The Co-evolution of Language and the Brain. London: Penguin.

DeGusta, D., Gilbert, W. H. and Turner, S. P. 1999. Hypoglossal canal size and hominid speech. Proceedings of the National Academy of Sciences of the USA, 96(4): 1800-4.

Dessalles, J. L. 2000. Language and hominid politics. In The Evolutionary Emergence of Language: Social Function and the Origins of Linguistic Form (eds C. Knight, M. Studdert-Kennedy and J. Hurford). Cambridge: Cambridge University Press, pp. 62-80.

Dibble, H. 1989. The implications of stone tool types for the presence of language during the Lower and Middle Palaeolithic. In The Human Revolution (eds P. Mellars and C. Stringer). Edinburgh: Edinburgh University Press, pp. 415-32.

Duchin, L. E. 1990. The evolution of articulate speech: comparative anatomy of the oral cavity in Pan and Homo. Journal of Human Evolution, 19: 687-97.

Dunbar, R. I. M. 1993. Co-evolution of neocortical size, group size and language in humans. Behavioral and Brain Sciences, 16: 681-94.

Dunbar, R. I. M. 1996. On the evolution of language and kinship. In The Archaeology of Human Ancestry (eds J. Steele and S. Shennan). London: Routledge, pp. 380-96.

Eibl-Eibesfeldt, I. 1989. Human Ethology. New York: Aldine de Gruyter.

Finlay, B. L. and Darlington, R. B. 1995. Linked regularities in the development and evolution of mammalian brains. Science, 268: 1578-84. 
Finlay, B. L., Darlington, R. B. and Nicastro, N. 2001. Developmental structure in brain evolution. Behavioral and Brain Sciences, 24: 298-308.

Foley, R. 1987. Another Unique Species. London: Longmans.

Gamble, C. 1995. Personality most ancient. British Archaeology, 1: 6.

Gamble, C. 1996. Making tracks: hominid networks and the evolution of the social landscape. In The Archaeology of Human Ancestry (eds J. Steele and S. Shennan). London: Routledge, pp. 253-77.

Gamble, C. 1998. Palaeolithic society and the release from proximity: a network approach to intimate relations. World Archaeology, 29: 426-49.

Gamble, C. and Steele, J. 1999. Hominid ranging patterns and dietary strategies. In Hominid Evolution: Lifestyles and Survival Strategies (ed. H. Ullrich). Gelsenkirchen: Edition Archaea, pp. 396-409.

Gil-White, F. 2002. To evolve language, first, you need to have prestige. Abstract, Fourth International Conference on the Evolution of Language, Harvard.

Gould, S. J. and Vrba, E. S. 1982. Exaptation - a missing term in the science of form. Paleobiology, 8: 4-15.

Gowlett, J. A. J. 1996. The frameworks of early hominid social systems: how many useful parameters of archaeological evidence can we isolate? In The Archaeology of Human Ancestry (eds J. Steele and S. Shennan). London: Routledge, pp. 135-83.

Grassly, N. C., von Haeseler, A. and Krakauer, D. C. 2000. Error, population structure and the origin of diverse sign systems. Journal of Theoretical Biology, 206: 369-78.

Han, Y .S., Wang, J., Fischman, D. A., Biller, H. F. and Sanders, I. 1999. Slow tonic muscle fibers in the thyroarytenoid muscles of human vocal folds: a possible specialization for speech. Anatomical Record, 256: 146-57.

Hassan, F. 1981. Demographic Archaeology, London: Academic Press.

Houghton, P. 1993. Neandertal supralaryngeal vocal tract. American Journal of Physical Anthropology, 90: 139-46.

Isaac, G. L. 1976. Stages of cultural elaboration in the Pleistocene: possible archaeological indications of the development of language capabilities. Annals of the New York Academy of Sciences, 280: 275-88.

Isaac, G. L. 1989. The Archaeology of Human Origins. Cambridge: Cambridge University Press.

Kaplan, H., Hill, K., Lancaster, J. and Hurtado, A. M. 2000. A theory of human life history: diet, intelligence, and longevity. Evolutionary Anthropology, 9: 156-85.

Kay, R. F., Cartmill, M. and Balow, M. 1998. The hypoglossal canal and the origin of human vocal behaviour. Proceedings of the National Academy of Sciences of the USA, 95(9): 5417-19.

Kirby, S. 2001. Spontaneous evolution of linguistic structure: an iterated learning model of the emergence of regularity and irregularity. IEEE Transactions on Evolutionary Computation, 5: 102-10.

Knight, C. 1996. Darwinism and collective representations. In The Archaeology of Human Ancestry (eds J. Steele and S. Shennan). London: Routledge, pp. 331-46. 
Knight, C., Studdert-Kennedy, M. and Hurford, J. (eds) 2000. The Evolutionary Emergence of Language: Social Function and the Origins of Linguistic Form. Cambridge: Cambridge University Press.

Kohn, M. and Mithen, S. 1999. Handaxes: products of sexual selection? Antiquity, 73: 518-26.

Lachmann, M., Szamado, S. and Bergstrom, C. T. 2001. Cost and conflict in animal signals and human language. Proceedings of the National Academy of Sciences of the USA, 98: 13189-94.

Laitman, J. T., Heimbuch, R. C. and Crelin, E. S. 1978. Development change in a basicranial line and its relationship to the upper respiratory system in living primates. American Journal of Anatomy, 152: 467-82.

Leonard, W. R. and Robertson, M. L. 2000. Ecological correlates of home range variation in primates: implications for hominid evolution. In On the Move: How and Why Animals Travel in Groups (eds S. Boinski and P. Garber). Chicago: University of Chicago Press, pp. 628-48.

LePage, R. B. 1968. Problems of description in multilingual communities. Transactions of the Philological Society, 181: 189-212.

Lieberman, D. E., McCarthy, R. C., Hiiemae, K., Lieberman, P. and Palmer, J. B. 1998. New estimates of fossil vocal tract dimensions. Journal of Human Evolution, 34: A12-A13.

Lieberman, P. 1984. The Biology and Evolution of Language. Boston, MA: Harvard University Press.

Lieberman, P. 1994. Hyoid bone position and speech: reply to Dr Arensburg et al. (1990). American Journal of Physical Anthropology, 94: 275-8.

Lieberman, P., Crelin, E. S. and Klatt, D. 1972. Phonetic ability and related anatomy of the newborn, adult human, Neanderthal man and the chimpanzee. American Anthropologist, 74: 287-307.

Lieberman, P., Laitman, J. T., Reidenberg, J. S. and Gannon, P. J. 1992. The anatomy, physiology, acoustics and perception of speech - essential elements in analysis of the evolution of human speech. Journal of Human Evolution, 23: 447-67.

Livingstone, D. and Fyfe, C. 2000. Modelling language-physiology coevolution. In The Evolutionary Emergence of Language: Social Function and the Origins of Linguistic Form (eds C. Knight, J. Hurford and M. Studdert-Kennedy). Cambridge: Cambridge University Press, pp. 199-215.

Locke, J. L. 2001. Rank and relationships in the evolution of spoken language. Journal of the Royal Anthropological Institute, 7: 37-50.

Ludwig, B. and Harris, J. 1995. Handedness and knapping skill: their effects on Plio-Pleistocene lithic assemblage variability. Precirculated papers of the Third World Archaeological Congress, New Delhi.

McGrew, W. C. and Marchant, L. F. 1997. On the other hand: current issues in and meta-analysis of the behavioral laterality of hand function in nonhuman primates. Yearbook of Physical Anthropology, 40: 201-32.

McHenry, H. M. 1996. Sexual dimorphism in fossil hominids and its socioecological correlates. In The Archaeology of Human Ancestry (eds J. Steele and S. Shennan). London: Routledge, pp. 91-109. 
MacLarnon, A. M. and Hewitt, G. P. 1999. The evolution of human speech: the role of enhanced breathing control. American Journal of Physical Anthropology, 109: 341-63.

McNabb, J. 1996. More from the cutting edge: further discoveries of Clactonian bifaces. Antiquity, 70: 428-36.

McNabb, J. and Ashton, N. 1995. Thoughtful flakers. Cambridge Archaeological Journal, 5: 289-301.

Mazur, A. and Cataldo, M. 1989. Dominance and deference in conversation. Journal of Social and Biological Structures, 12: 87-99.

Mithen, S. 1994. Technology and society during the Middle Pleistocene. Cambridge Archaeological Journal, 4: 3-33.

Mithen, S. 1996. Social learning and cultural tradition. In The Archaeology of Human Ancestry (eds J. Steele and S. Shennan). London: Routledge, pp. 207-29.

Nettle, D. and Dunbar, R. I. M. 1997. Social markers and the evolution of reciprocal exchange. Current Anthropology, 38: 93-9.

Noble, W. and Davidson, I. 1991. The evolutionary emergence of modern human behaviour language and its archaeology. Man, 26: 223-53.

Nowak, M. A. and Krakauer, D. C. 1999. The evolution of language. Proceedings of the National Academy of Sciences of the USA, 96: 8028-33.

Nowak, M. A., Plotkin, J. B. and Krakauer, D. C. 1999. The evolutionary language game. Journal of Theoretical Biology, 200: 147-62.

Ohnuma, K., Aoki, K. and Akazawa, T. 1997. Transmission of tool-making through verbal and nonverbal communication: preliminary experiments in Levallois flake production. Anthropological Science, 105: 159-68.

Pinker, S. and Bloom, P. 1990. Natural language and natural selection. Behavioral and Brain Sciences, 13: 707-84.

Plavcan, J. M. 2000. Inferring social behaviour from sexual dimorphism in the fossil record. Journal of Human Evolution, 39: 327-44.

Pobiner, B. L. 1999. The use of stone tools to determine handedness in hominids. Current Anthropology, 40: 90-2.

Potts, R. 1992. The hominid way of life. In The Cambridge Encyclopedia of Human Evolution (eds S. Jones, R. Martin and D. Pilbeam). Cambridge: Cambridge University Press, pp. 325-34.

Power, C. and Watts, I. 1996. Female strategies and collective behaviour. In The Archaeology of Human Ancestry (eds J. Steele and S. Shennan). London: Routledge, pp. 306-30.

Rilling, J. K. and Insel, T. R. 1999. The primate neocortex in comparative perspective using magnetic resonance imaging. Journal of Human Evolution, 37: 191-223.

Roberts, M. 1995. Boxgrove man [letter]. British Archaeology, 3: 10.

Sanders, I. 2002. Human tongue, pharynx and vocal fold muscles contain slow tonic muscle, a distinct class of muscle that may have evolved for speech. Abstract, Fourth International Conference on the Evolution of Language, Harvard. 
Semendeferi, K. and Damasio, H. 2000. The brain and its main anatomical subdivisions in living hominoids using magnetic resonance imaging. Journal of Human Evolution, 38: 317-32.

Semenov, S. A. 1961. Traces of work on tools and evidence that Neanderthal men worked with their right hand (in Russian). Korotkie Soobshcheniya Instituta Arkheologii (Short Bulletins of the Institute of Archaeology), 84.

Semenov, S. A. 1964. Prehistoric Technology: An Experimental Study of the Oldest Tools and Artefacts from Traces and Manufacture and Wear. New Jersey: Barnes \& Noble Books.

Shennan, S. J. and Steele, J. 1999. Cultural learning in hominids: a behavioural ecological approach. In Mammalian Social Learning: Comparative and Ecological Perspectives (eds H. O. Box and K. R. Gibson). Cambridge: Cambridge University Press, pp. 367-88.

Smith, E. A. and Winterhalder, B. 1992. Evolutionary ecology and the social sciences. In Evolutionary Ecology and Human Behaviour (eds E. A. Smith and B. Winterhalder). New York: Aldine de Gruyter, pp. 3-23.

Steele, J. 1994. Communication networks and dispersal patterns in human evolution: a simple simulation model. World Archaeology, 26: 126-43.

Steele, J. 1996. On predicting hominid group sizes. In The Archaeology of Human Ancestry: Power, Sex and Tradition (eds J. Steele and S. Shennan). London: Routledge, pp. 230-52.

Steele, J. 1998. Cerebral asymmetry, cognitive laterality, and human evolution. Current Psychology of Cognition, 17: 1202-14.

Steele, J. 2000. Handedness in past human populations: skeletal markers. Laterality, 5: 193-220.

Steele, J. in press. When did directional asymmetry enter the record? In The Speciation of Modern Homo sapiens (ed. T. J. Crow). Proceedings of the British Academy Vol. 106.

Steele, J., Quinlan, A. and Wenban-Smith, F. 1995. Stone tools and the linguistic capabilities of earlier hominids. Cambridge Archaeological Journal, 5: 245-56.

Steels, L. 1997. The synthetic modeling of language origins. Evolution of Communication, 1: 1-34.

Steels, L. 1998. The origins of syntax in visually grounded robotic agents. Artificial Intelligence, 103: 133-56.

Toth, N. 1985. Archaeological evidence for preferential right-handedness in the Lower and Middle Pleistocene, and its possible implications. Journal of Human Evolution, 14: 607-14.

Widlok, T. 1997. Orientation in the wild: the shared cognition of Haillom Bushpeople. Journal of the Royal Anthropological Institute, 3: 317-32.

Wynn, T. 1991. Tools, grammar and the archaeology of cognition. Cambridge Archaeological Journal, 1: 191-206. 